\title{
LARGE MICROBIOTA SURVEY REVEALS HOW THE MICROBIAL ECOLOGY OF COOKED HAM IS SHAPED BY DIFFERENT PROCESSING STEPS.
}

Marine Zagdoun ${ }^{1}$, Gwendoline Coeuret ${ }^{1}$, Méry N'Dione ${ }^{1}$, Marie-Christine ChampomierVergès $^{1}$ and Stéphane Chaillou ${ }^{1, \#}$.

${ }^{1}$ Université Paris-Saclay, INRAE, AgroParisTech, MIcalis Institute, 78350, Jouy-en-Josas, France

\#Author for correspondence: stephane.chaillou@inra.fr 


\begin{abstract}
The production of cooked ham involves numerous steps shaping the microbial communities of the final product, with consequences on spoilage metabolites production. To identify the main factors driving the ecology of ham and its spoilage, we designed a study encompassing five variables related to ham production: type of storage during meat transportation, churning speed, drain-off time, slicing line and $\mathrm{O}_{2}$ packaging permeability. We obtained about 200 samples from the same facility and we characterized i) their microbiota based on gyrB amplicon sequencing $i$ ) their production of spoilage-related metabolites based on E-Nose analysis and enzymatic assays. The slicing was the most critical step, shaping two general types of microbiota according to the slicing line: one dominated by Carnobacterium divergens and another one dominated by Leuconostoc carnosum and Serratia proteamaculans. Regarding metabolites production, L. carnosum was associated to D-lactic acid, ethanol and acetic acid production, whereas Serratia proteamaculans was associated to acetic acid production. This last species prevailed with highly $\mathrm{O}_{2}$-permeable packaging. Within a given slicing line, we observed campaign-based variations, with Lactobacillus sakei, Leuconostoc mesenteroides and Carnobacterium maltaromaticum prevalent in summer. L. sakei was associated with Llactic acid production and C. maltaromaticum with formic and acetic acid productions.
\end{abstract}

\title{
KEYWORDS
}

Microbial ecology; cooked ham; process; spoilage metabolites 


\section{INTRODUCTION}

The production of cooked ham involves many processing steps, with each being a potential source of bacterial contamination or re-contamination post-cooking. As a consequence, the shelf-life of this meat product is strongly dependent on the microbiota dynamic through these various steps. It is also related with how the process parameters will influence the metabolic activities of the growing bacterial species during storage (Audenaert et al., 2010; Dušková et al., 2016; Han et al., 2011; Raimondi et al., 2019; Piotrowska-Cyplik et al., 2017; Vasilopoulos et al., 2010).

The variability of ham begins at the most upstream step of the process as initial raw pork cuts usually contain diverse microbiota depending on the slaughtering and butchering process (De Filippis et al., 2013; Wheatley et al., 2014). Bacterial contamination usually increases in the processing plants through the contamination of surfaces and tools (Stellato et al., 2016) along the various processing steps (Hultman et al., 2015; Samelis et al., 1998), as well as with ingredients used in the brine such as spices (Benson et al., 2014). Furthermore, the efficiency of brining requires a churning incubation time, a step which was shown to participate in the selection of some bacterial species, such as Brochothrix thermosphacta or Carnobacterium divergens (Samelis et al., 1998). After churning, bacterial load is close to $10^{5} \mathrm{cfu} / \mathrm{g}$ (Dušková et al., 2016; Samelis et al., 1998; Vasilopoulos et al., 2010). The following cooking step at $70^{\circ} \mathrm{C}$ generally reduces the bacterial load back to practically zero (Dušková et al., 2016; Vasilopoulos et al., 2010). However, some studies showed that thermoduric strains such as Leuconostoc carnosum or Weissella viridescens could resist cooking (Björkroth et al., 1998; Comi and lacumin, 2012). Other studies showed that Leuconostoc mesenteroides and $L$. carnosum were also brought by the post-cooking downstream processing steps, either through the hands of worker while de-molding, via the slicing machine, the packaging or even via the air (Björkroth and Korkeala, 1997; Dušková et al., 2016; Mol et al., 1971; Samelis et al., 1998). Then, depending on the storage temperatures and the type of packaging used, a final reduction 
of bacterial diversity takes place, selecting psychrotrophic anaerobic microbiota (Audenaert et al., 2010; Chaillou et al., 2015), the activity of which will eventually cause spoilage.

Thus, if the microbiota of ham after cooking does probably result of both surviving microbiota after cooking and post-cooking contaminations, it is yet unclear to what extent raw meat and pre-cooking process steps can shape the final microbiota of ham. In this line of view, Geeraerts and co-workers (2017) have nevertheless underlined the variability of bacterial communities of hams between different facilities. They have also shown that those communities can vary according to the sampling period. Even hams produced within a same facility revealed to harbor variable communities (Audenaert et al., 2010; Vasilopoulos et al., 2010, 2008). More recently, Raimondi and co-workers (2019) described a wide variability in the microbial assemblages of cooked ham from ten different producers in Europe. Despite the low number of ham analyzed in this study (14 different ham in total), their work showed that the quality of hams at the end of the storage period, as measured by organic volatile compounds analysis, was highly dependent on the microbiota present on these products.

Given this complex processing, the spoilage microbial ecology of ham remains difficult to decipher and it is hard for the meat industry to implement useful support decision tool for process management and prevention of food losses. To us, the works described above represent a revealing illustration of the necessity of adopting a large sampling strategy and robust statistical analysis in order to capture the overwhelming variability created by the many steps of cooked ham processing. The aim of this study was to provide such type of large-scale approach based on a factorial design to allow the analysis of variations within five main processing steps. We focused our analysis on a single processing factory, located in France, and by designing a large sampling (over 200 samples), spanning a production period of six months. To improve our accuracy in tracing bacterial taxa throughout processing, we performed gyrB amplicon sequencing, a powerful alternative to 16S rRNA gene sequencing for accurate bacterial identification at the intra-species level (Poirier et al., 2018b). We then combined this diversity analysis with the quantification of $\mathrm{pH}$ and of five metabolites (ethanol, 
bioRxiv preprint doi: https://doi.org/10.1101/865857; this version posted December 5, 2019. The copyright holder for this preprint (which was not certified by peer review) is the author/funder. All rights reserved. No reuse allowed without permission.

D- and L-lactate, acetate, formate), used as indicators of fermentation end-products contributing to the pattern of ham spoilage. 


\section{MATERIALS AND METHODS}

\subsection{Industrial ham production}

Raw pork meat for the production of ham was obtained from a single slaughterhouse. After deboning, raw meat was transported to the ham production factory (see processing step in Table 1). Meat was then brined to reach a final concentration (wt/wt) in the product of $1.4 \%$ sodium chloride, $0.5 \%$ glucose, $0.08 \%$ sodium nitrite, and $0.03 \%$ sodium ascorbate. Each subbatch (determined by variations in processing parameters; see Table 1) was then churned and molded into individual loaves and cooked until the center reached $70^{\circ} \mathrm{C}$. After cooking, draining-off, and slicing, hams were packed under $50 \% \mathrm{CO}_{2} / 50 \% \mathrm{~N}_{2}$ modified-atmosphere conditions.

\subsection{Ham storage conditions}

Industrial hams were sent to our laboratory immediately after packaging using refrigerated transportation (2 days at $4^{\circ} \mathrm{C}$ ). Hams were stored in FRIOCELL 55 refrigerated incubators (MMM Medcenter, Planegg, Germany) at $4^{\circ} \mathrm{C}$ for 5 more days, then at $8^{\circ} \mathrm{C}$ until the Use-ByDate (UBD) or for 15 more days (past UBD). Control samples $\left(T_{0}\right)$ were immediately frozen at $-20^{\circ} \mathrm{C}$ after packaging and sent frozen to our laboratory. At the end of storage, all ham samples were frozen at $-20^{\circ} \mathrm{C}$ until $\mathrm{pH}$ measurement, DNA extraction, and recovery of the microbiota were performed.

\subsection{Gas and pH measurements}

$\mathrm{O}_{2}$ and $\mathrm{CO}_{2}$ levels were quantified using an Oxybaby probe (WITTGAS, Morsang-sur-Orge, France). Then, $\mathrm{pH}$ was measured using a FiveEasy FE20 surface $\mathrm{pH}$ probe (Mettler Toledo AG, Schwerzenbach, Schwitzerland). The $\mathrm{pH}$ data correspond to a mean of five measurements per sample at various areas on the slices.

\subsection{Identification and relative quantification of volatile organic compounds.}

Volatile compounds in ham samples were detected with a Heracles II electronic nose (Alpha MOS, Toulouse, France), using ultra-fast gas chromatography. Samples were analyzed on two 
independent columns of different polarity (nonpolar MXT-5 and medium polar MXT-1701, length $10 \mathrm{~m}$ each) for an accurate identification of compounds using their KOVAT number. Agrochembase, an internal database of AlphaMOS, provided information on chemical analysis and sensorial olfactory descriptors.

\subsection{Microbiota recovery and bacterial load quantification}

For each ham sample, four independent DNA extractions were performed (each of one quarter of a ham) and were subsequently pooled. Our protocol was based on that of Fougy and colleagues (Fougy et al., 2016), adapted as follows: $20 \mathrm{~g}$ of meat were homogenized for $2 \mathrm{x}$ $30 \mathrm{~s}$ in a stomacher bag (BagPage, Interscience, Saint-Nom-la-Bretèche, France) with $40 \mathrm{~mL}$ of sterile ultrapure water supplemented with 1\% Tween 80 (Acros Organics, Waltham, USA). Large meat debris were filtered from the bag and $33 \mathrm{~mL}$ of the microbe-containing ham solution was collected. One milliliter was reserved to estimate viable bacterial counts, and the remaining $32 \mathrm{~mL}$ were centrifuged at $500 \times \mathrm{g}$ for $3 \mathrm{~min}$ at $4^{\circ} \mathrm{C}$ (Allegra X-15R, Beckman Coulter, Villepinte, France) to spin down the remaining meat fibers and debris. A maximum volume of $25 \mathrm{~mL}$ of supernatant was then centrifuged at $3000 \times g$ for $5 \mathrm{~min}$ at $4^{\circ} \mathrm{C}$ to spin down microbial cells. The supernatant was frozen at $-80^{\circ} \mathrm{C}$ for further metabolite quantification, and the bacterial pellets were washed in $1 \mathrm{~mL}$ of sterile ultrapure water, centrifuged at $3000 \times g$ for 5 min at $4^{\circ} \mathrm{C}$ (Centrifuge 5424, Eppendorf, Hamburg, Germany), and frozen at $-20^{\circ} \mathrm{C}$ for bacterial DNA extraction. For quantification of the bacterial population, the reserved $1 \mathrm{~mL}$ of ham solution was subjected to decimal dilutions and plated on Columbia agar with $5 \%$ sheep blood (Thermo Fisher Scientific, Illkirch Graffenstaden, France) in order to estimate the overall cultivable bacterial load. Bacterial colonies were counted after 72 hours of incubation at $20^{\circ} \mathrm{C}$.

\subsection{Quantification of end-products}

Supernatants of ham samples were clarified to eliminate proteins using the Carrez clarification kit (Merck KGaA, Darmstadt, Germany). Proteins were precipitated via the successive addition of $600 \mu \mathrm{L}$ of Carrez reagent I and $600 \mu \mathrm{L}$ of Carrez reagent II to $5 \mathrm{~mL}$ of supernatant. After adjusting the $\mathrm{pH}$ to be between 7.5 and 8.5 (required for enzymatic assays), the samples were 
centrifuged at $5000 \times g$ for 20 min to spin down precipitated proteins. Residual proteins were then eliminated by filtration on $0.22-\mu \mathrm{m}$ high-protein-retention Ministart syringe filters (Sartorius Stedim Biotech $\mathrm{GmbH}$, Goettingen, Germany). Megazyme enzymatic assays (Megazyme Wicklow, Ireland) were used to quantify concentrations of ethanol (K-ETOH), L- and D-lactic acid (K-LAC), acetic acid (K-ACET), and formic acid (K-FORM), according to the manufacturer's instructions. For all kits, NADH absorbance was measured using a microplate reader (SYNERGY Mx, BIOTEK, Colmar, France).

All calculations of end-product concentrations took into account the dilution factor $(20 \mathrm{~g}$ of meat in $40 \mathrm{~mL}$ of sterile water with $1 \%$ Tween 80 for microbiota recovery, and addition of $1.2 \mathrm{~mL}$ of Carrez reagents) in order to estimate the real concentrations in meat.

\subsection{Bacterial DNA extraction and quality control}

Bacterial DNA was extracted with a High Pure PCR Template Preparation kit (Roche Diagnostics Ltd, Burgess Hill, West Sussex, UK), with the following adaptations: for cellular lysis, bacterial pellets were resuspended in $200 \mu \mathrm{L}$ PBS that contained lysozyme (final concentration of $20 \mathrm{mg} \cdot \mathrm{mL}^{-1}$ ) and Mutanolysin (12U). This solution was incubated at $37^{\circ} \mathrm{C}$ for 60 min in a water bath (Polystat 86602, Bioblock Scientific, Illkirch, France). Then, $200 \mu \mathrm{L}$ of binding buffer and $40 \mu \mathrm{L}$ of Proteinase $\mathrm{K}$ were added; the solution was vortexed and incubated at $70^{\circ} \mathrm{C}$ for $30 \mathrm{~min}$ in a second water bath (APELEX, JULABO, Seelbach, Germany). DNA was precipitated and purified on columns according to the manufacturer's instructions, with the exception of a reduction of the final elution volume to $100 \mu \mathrm{L}$ in order to concentrate the DNA. Technical replicates for each ham sample were pooled following DNA extraction and frozen at $-20^{\circ} \mathrm{C}$. After pooling, double-strand DNA quantification was performed with the Qubit dsDNA HS assay kit (Invitrogen, Carlsbad, USA).

\subsection{PCR protocols for gyrB and 16S V3-V4 rRNA gene amplification, purification and quality control of amplicons}


The internal fragment of the gyrB gene (around $280 \mathrm{bp}$ ) was amplified as described in (Barret et al., 2015; Poirier et al., 2018b) with AccuPrime Taq DNA polymerase (Invitrogen, Carlsbad, USA) and F64 and R353 degenerated primers (5'-MGNCCNGSNATGTAYATHGG-3' and 5'CNCCRTGNARDCCDCCNGA-3', respectively). The forward and reverse primers carried the Illumina adapters 5'-CTTTCCCTACACGACGCTCTTCCGATCT-3' and 5'GGAGTTCAGACGTGTGCTCTTCCGATCT-3', respectively. To balance the high degeneration rate of the primers, the final primer concentration was increased to $1000 \mathrm{nM}$. PCR was performed on $10 \mathrm{ng}$ of each pooled DNA sample using a PTC-200 thermal cycler (Peltier, BioRad, Hercules, USA). Amplification started with an initial denaturation step of 2 min at $94^{\circ} \mathrm{C}$. This was followed by 35 cycles of denaturation $\left(94^{\circ} \mathrm{C}\right.$ for $\left.30 \mathrm{~s}\right)$, annealing $\left(55^{\circ} \mathrm{C}\right.$ for $60 \mathrm{~s})$, and elongation $\left(68^{\circ} \mathrm{C}\right.$ for $\left.90 \mathrm{~s}\right)$, and ended with a final elongation step of $10 \mathrm{~min}$ at $68^{\circ} \mathrm{C}$. PCR bias was minimized by pooling three independent PCR replicates per sample.

To assess potential biases in the recovered microbial diversity, controls using $16 \mathrm{Sr}$ V3-V4 rRNA gene amplifications (around $450 \mathrm{bp}$ ) were performed on fourteen selected samples; these amplifications used MolTaq 16S DNA polymerase (Invitrogen, Carlsbad, USA) and two primers that targeted the V3 and V4 region (Klindworth et al., 2013; Poirier et al., 2018a), 5'ACGGRAGGCWGCAGT-3' and 5'-TACCAGGGTATCTAATCCT-3'. The forward and reverse primers carried the Illumina adapters 5'-CTTTCCCTACACGACGCTCTTCCGATCT-3' and 5'GGAGTTCAGACGTGTGCTCTTCCGATCT-3', respectively. The final primer concentration was $200 \mathrm{nM}$. PCR was performed on $10 \mathrm{ng}$ of the pooled DNA sample with a PTC-200 thermal cycler, with the following cycling parameters: initial denaturation for $1 \mathrm{~min}$ at $94^{\circ} \mathrm{C}$, followed by 30 cycles of denaturation $\left(94^{\circ} \mathrm{C}\right.$ for $\left.60 \mathrm{~s}\right)$, annealing $\left(65^{\circ} \mathrm{C}\right.$ for $\left.60 \mathrm{~s}\right)$, and elongation $\left(72^{\circ} \mathrm{C}\right.$ for $60 \mathrm{~s}$ ), and a final elongation step of $10 \mathrm{~min}$ at $72^{\circ} \mathrm{C}$. PCR bias was minimized by pooling three independent PCR products per sample.

The gyrB and 16S rRNA gene amplicons were purified using a QIAquick kit (Qiagen, Hilden, Germany) and their quality and concentration were checked with a DNA1000 chip (Agilent Technologies, Paris, France). 


\subsection{Illumina MiSeq library preparation and sequencing}

In order to pool and sequence a large number of libraries simultaneously, samples were coded with individual barcode sequences during library preparation: 6-bp unique indices and the second part of the forward (5'-AATGATACGGCGACCACCGAGATCTACACT-3') and reverse adapters (5'-CAAGCAGAAGACGGCATACGAGAT-NNNNNN-GTGACT-3') were added during the Illumina PCR. PCR comprised an initial denaturation step at $94^{\circ} \mathrm{C}$ for $10 \mathrm{~min}$, followed by 12 amplification cycles of $94^{\circ} \mathrm{C}$ for $1 \mathrm{~min}, 65^{\circ} \mathrm{C}$ for $1 \mathrm{~min}$, and $72^{\circ} \mathrm{C}$ for $1 \mathrm{~min}$, and a final elongation step at $72^{\circ} \mathrm{C}$ for $10 \mathrm{~min}$. Amplicons were then purified on Clean PCR magnetic beds (Clean NA, Alphen aan den Rijn, The Nederlands). Their concentration after purification was estimated with a Nanodrop spectrophotometer (Thermo Scientif, Whaltham, USA) and their quality was checked using a Fragment Analyzer (AATI, Santa Clara, USA). Reads from libraries were pooled in equal amounts, in order to obtain a final concentration for sequencing between 5 and $20 \mathrm{nM}$. Pools were denatured with $\mathrm{NaOH}$, mixed with the PhiX control library v3 (diluted to 7 pM; Illumina, San Diego, USA), and loaded on an Illumina MiSeq cartridge. The MiSeq Reagent Kit v3 (2×300 paired-end reads, 15 Gb output) was used according to the manufacturer's instructions. The quality of the obtained sequences was checked with FastQ files generated at the end of the run (MiSeq Reporter Software, Illumina, USA) and additional PhiX Control. The corresponding pairs of sequences were then attributed to their respective samples using the individual multiplexing barcodes.

\subsection{Quality control of raw MiSeq reads and OTU clustering parameters}

Samples were sequenced in three runs (295 amplicons of gyrB analyzed in runs 1 and 2 and 28 amplicons of 16S rRNA gene analyzed in run 3). Quality controls indicated a quality score of at least 30 for $91 \%$ of the reads and a median number of $44,022 \pm 33,312$ reads per sample.

We used FastQC (https://github.com/s-andrews/FastQC) to assess sequencing quality. Paired-end sequences were then merged using PEAR v0.9.10 (Zhang et al., 2014) with a minimum overlap of 20 nucleotides for both gyrB and 16S rRNA gene and a threshold p-value of 0.01 . We retained merged sequences with a size of $280 \pm 50$ bp for gyrB and $450 \pm 50 \mathrm{bp}$ 
for 16S rRNA gene. Primer-binding sequences were removed using CUTADAPT v1.12 (Martin, 2011) with a maximum error rate of 0.01 ; low-quality bases at the ends of the merged sequences (quality threshold of 20 , sequences with ambiguous bases $\mathrm{N}$ ) were eliminated using SICKLE v1.330 (https://github.com/najoshi/sickle).

Quality-filtered merged sequences were then loaded in the FROGS (Find Rapidly OTUs with Galaxy Solutions) pipeline (Escudié et al., 2018) and dereplicated. SWARM clustering (Mahé et al., 2014) was performed using a maximal aggregation distance of three nucleotides for $16 \mathrm{~S}$ rRNA gene sequences; for gyrB sequences, clustering was more stringent, with a maximal aggregation distance of two nucleotides in order to potentially assign OTUs to the subspecies level. Chimeras were removed using the VCHIM feature of the VSEARCH package (https://github.com/torognes/vsearch). Clusters were further filtered to remove spurious lowabundance OTUs arising from sequencing artifacts. As reported by Bokulich and colleagues (2013), these types of OTUs appear in very few samples with very low abundance $(<0.005 \%)$. Therefore, for the gyrB reads we retained OTUs with at least 100 reads in the whole dataset $(0.002 \%$ of 5.9 million reads in total), and for the $16 \mathrm{~S}$ rRNA gene used as controls, we retained OTUs with at least 10 reads in the whole dataset, since there were fewer samples than for gyrB $(0.0008 \%$ of 1.3 million reads in total).

These steps resulted in the retention of 238 gyrB OTUs and 88 16S rRNA gene OTUs. An otu_table with the respective normalized abundances of the different OTUs in each sample was constructed for both the gyrB and 16S rRNA gene datasets and is available as supplementary dataset S2. The total number of reads per sample was normalized based on the median sequencing depth of all samples.

\subsection{Taxonomic assignment and phylogenetic tree construction}

For certain species of Firmicutes, PCR amplification of gyrB can also recover the parE gene, which encodes the $\beta$ subunit of DNA topoisomerase IV. In order to determine which of the two genes had been amplified for each species, the OTU sequences were blasted against the 
gyrB/parE databases established by Poirier and colleagues (2018b), using the Blastn+ algorithm (Camacho et al., 2009) for taxonomic assignment. Both gyrB and parE OTUs were retained in our diversity analysis. We considered taxonomic assignments to be valid when 94\% of a sequence matched over 200 bp of coverage; valid matches were assigned identifications at least at the species level and in some cases at the subspecies level.

Sequences of 16S rRNA gene were identified using the Ribosomal Database Project (RDP) Classifier (Wang et al., 2007) and the SILVA 128 SSU databases (Quast et al., 2013). Taxonomic assignment of the different OTUs to genera and, when possible, to the species level was carried out based on a threshold of $97 \%$ identity. The Ez-taxon-e database was used to identify uncultured species (Kim et al., 2012) that had not been previously identified with SILVA.

For each dataset, phylogenetic trees were created with SeaView software (Gouy et al., 2010) using the Kimura-2-parameter algorithm (Kimura, 1980) as distance estimator. Distance matrices were converted to trees using the BioNJ neighbor-joining method (Gascuel, 1997).

\subsection{Alpha/beta diversity and statistical analyses}

Bacterial diversity analyses were performed using the phyloseq package (v1.24.2) of $R$ (McMurdie and Holmes, 2013). The relative abundance of bacterial species in samples was plotted with the function plot_composition. A dendrogram based on Bray-Curtis dissimilarity index values was plotted with the function as.dendogram, using the ward.D2 method, and visualized with the function fviz_dend in the gglot2 package (v3.0.0) of R. To visualize the results of principal coordinate analyses (PCoA), samples were first ordered according to BrayCurtis dissimilarity index values using a non-metric dimensional scaling (NMDS) approach, and then plotted with the function s.class within the ade4 package (v1.7-13) of R (Chessel et al., 1987). Bacterial diversity was compared among different groups of samples with permutational ANOVA, specifically using the adonis function within the vegan package (v2.52; https://github.com/vegandevs/vegan) of R. Boxplots were drawn with the ggboxplot function 
from R's ggpubr package, v0.1.8. In Figure 5, the significance of differences between groups of samples was assessed with ANOVA, followed by a Student's t-test. In Figure S5, the significance of the differences between groups of samples was estimated with a Mann \& Whitney non-parametric test, since the number of samples was less than 30 for each group. For correlation plots, the correlation coefficient was calculated with the cor function using the Pearson method and visualized using the corrplot function within the corrplot package, v0.84 (https://github.com/taiyun/corrplot). A heatmap was drawn with the plot_heatmap function of the ggplot2 package, v3.0.0 (Wickham, 2010).

Data availability. Raw paired sequences have been deposited in the Sequence Read Archive database under the accession numbers SAMN11405181 to SAMN11405379 and SAMN11936727 to SAMN11936732, corresponding to BioProject PRJNA532535.

\section{RESULTS}

\subsection{Sampling strategy}

Through a survey of a single production unit, we identified five processing steps as potential sources of bacterial contamination, with each step potentially able to induce variations in bacterial species diversity and population level. These steps were the transportation of raw meat from the slaughterhouse to the ham-producing factory, churning, drain-off after cooking, slicing, and packing. Although this is an industrial process, over the course of a year, these steps are often subject to important variations in duration or in exposure to aerobiosis/anaerobiosis conditions. To assess the role of each step in shaping bacterial diversity, we set up a complete factorial design in which each of the five processing steps was sampled at two different levels, chosen specifically from those encountered in the focal production unit (Table 1). With this sampling design, a total of 32 hams were sampled, each produced under slightly different conditions (Fig. 1). Although all meat was purchased from the same slaughterhouse, we also assessed possible variations due to changes in the initial meat microbiota over an extended period; specifically, we conducted four separate sampling 
campaigns over a period of six months: in June (Campaign C1), August (Campaign C2), September (Campaign C3), and November (Campaign C4). Overall, 128 different hams (32 x 4) were sampled.

The variations in ham production that were evaluated by our factorial design were necessarily accompanied by variations in the total length of processing, from a minimum of 12 days to a maximum of 28 days. However, optimal operational procedures for slicing and packing required that these two steps be carried out with the shortest delay possible. Due to these constraints, each sampling campaign required the use of four different batches of raw meat for ham production, as shown in Figure S1. Although our study was primarily focused on the final bacterial diversity of ham (after cooking, slicing, and packing), we incorporated some controls by measuring the bacterial diversity before cooking (after churning) in two campaigns (C2 and C3). Finally, each cooked ham was analyzed at two storage times: at the use-by date (UBD) and after 15 days of extended storage (past UBD), corresponding respectively to samples stored at $8^{\circ} \mathrm{C}$ for 28 and 43 days (see Fig. S1). Altogether, the sampling comprised a total of 256 hams.

\subsection{Bacterial diversity in cooked ham was low and was shaped by both pre- and post-cooking processing steps}

Bacterial diversity was assessed with MiSeq paired-end gyrB amplicon sequencing, which enabled accurate taxonomic assignment of OTUs to the species level (Poirier et al., 2018b). Amplification of 16S rRNA gene was performed for fourteen samples as a control and confirmed that there was no bias in species detection resulting from the use of gyrB (see supplementary Fig. S2). For gyrB amplicon sequencing, the success rate for DNA extraction and sequencing was around $80 \%$, which yielded a dataset of 200 samples out of the 256 initially planned. However, the failed samples were scattered throughout the factorial design and campaigns and thus did not reduce the effectiveness of our statistical analysis. From the whole gyrB dataset, 157 OTUs were identified and assigned to 44 different bacterial species (average of four OTUs per species, see supplementary dataset S3 for a table detailing OTU 
abundance). As shown in Table 2, the mean number of species identified per sample was approximately 15 species.

The majority of the bacterial diversity in cooked ham samples was represented by approximately fourteen different species in various combinations, which together corresponded to a mean of $98 \%$ of the total relative bacterial abundance (Fig. 2). To correlate differences in bacterial community composition to variations in processing steps, we performed a comparative compositional analysis using the Bray-Curtis dissimilarity index and non-metric multi-dimensional scaling (NMDS). This analysis revealed that ham bacterial communities at the UBD were not significantly different from those past the UBD, and further revealed that slicing line and sampling campaign were the main factors that shaped these communities (Fig. 3). In order to better understand these differences, bacterial assemblages were plotted according to these two processing parameters. Figure 4 illustrates how these parameters influenced both the relative abundance and presence/absence of core bacterial species. Briefly, the identity of the slicing line influenced the overall distribution of multiple bacterial genera (e.g., Carnobacterium in line A versus Leuconostoc and Serratia in line B). Within each genus, the slicing line also influenced the identity of the species present (e.g., C. divergens in line A versus $C$. maltaromaticum in line B). Certain species also appeared in multiple sampling campaigns of a given line (e.g., L. mesenteroides present in campaign C1 and C2 for line A; L. gelidum subsp. gelidum present in campaign C3 for line B; L. sakei present in campaign C1 for line B; C. maltaromaticum present in campaign C2 and C3 for line B).

It should be noted that the effect of churning time on the cooked ham microbiota was also revealed to be statistically significant, although it was less obvious from the NMDS analysis (see supplementary Fig. S4). Indeed, this effect was mostly significant in cooked ham from slicing line A. Similarly, $\mathrm{O}_{2}$ packaging permeability had a significant effect on the microbiota of line B only. We linked this observation to the fact that S. proteamaculans, the only dominant Proteobacteria found among cooked ham samples, was much more prevalent in samples from slicing line B (in $58 \%$ of samples from line B versus $17 \%$ of samples from line A). Moreover, 
samples of line B differed greatly in the relative abundance of this species, which suggests the influence of another processing step than the slicing line. Indeed, when samples from line B were analyzed separately, we observed that S. proteamaculans was significantly more abundant in samples produced with processing steps that had higher oxygen levels (air transportation and high $\mathrm{O}_{2}$ packaging permeability; see Fig. 5 Panel $\left.\mathrm{P} 1\right)$. We also noted that, at the UBD, $\mathrm{O}_{2}$ was not detected in cooked ham samples packed in highly permeable packaging (data not shown). Therefore, any $\mathrm{O}_{2}$ that permeated the packaging seemed to have been rapidly consumed by the microbiota. In slicing line $A$, instead, the relative abundance of C. divergens appeared to be correlated with churning, as the abundance of this species increased in ham that was churned quickly (see Fig. 5 Panel P2).

To summarize, our data indicated that the four main processing parameters that shaped the types of bacterial communities present in cooked ham were, in decreasing order of influence, identity of slicing line, sampling campaign (different meat batches over six months of sampling), $\mathrm{O}_{2}$ permeability of packaging, and churning speed. Two of these processing steps occurred post-cooking (slicing line and packaging type) and two occurred pre-cooking (campaign and churning speed).

\subsection{Bacterial species present in cooked ham mostly originated from raw meat} and were among the most abundant species in meat samples after churning Because the slicing line had a strong influence on the type of microbiota present in ham samples, even in samples that originated from the same batch of raw meat, we next investigated whether the bacterial species identified after cooking were also present before cooking. Furthermore, the slight influence of pre-cooking factors such as sampling campaign and churning speed on the relative abundances of certain species raised questions regarding the effectiveness of the cooking step in controlling bacterial populations. As shown in Fig. 6, we found that the most abundant species in cooked hams were also present in raw meat after churning: C. divergens, L. sakei, C. maltaromaticum, L. carnosum, L. gelidum, S. proteamaculans, and L. mesenteroides, in decreasing order of abundance. Overall, cooking 
eliminated only $50 \%$ of the species present in raw churned meat, mostly those that were subdominant. Among species that were highly abundant in raw churned meat, the cooking step eliminated Proteobacteria (e.g., Pseudomonas species) more effectively than Firmicutes, with the exception of S. proteamaculans. However, we also found evidence for post-cooking contamination, as illustrated by the presence of species in cooked hams that had not been detected in raw churned meat for those sampling campaigns (e.g., Vagoccocus fluvialis).

\subsection{The production of fermentation-derived metabolites, used as spoilage} indicators, was species-dependent and driven by population abundance.

Next, we focused our analysis on the consequences of these different community patterns for the quality of the cooked ham. Of the important characteristics of spoilage, we chose to assess bacterial load, decrease in $\mathrm{pH}$ (an indicator currently used in the meat industry to detect spoilage), and the production of volatile organic compounds (VOCs). Additionally, since ham contains glucose, we also measured the concentration of end-products from the mixed-acid fermentation of pyruvate (both L- and D-lactic acid, acetic acid, formic acid, and ethanol). Because no differences were detected in the bacterial communities at the two sampling times (UBD or past UBD), we narrowed our analysis to UBD samples only ( $n=128)$ in order to determine whether any significant differences in spoilage characteristics were detectable in hams at the end of storage, prior to consumption.

At the UBD, the bacterial load of cooked hams from slicing line $A\left(7.1 \pm 1.0 \log _{10} \mathrm{cfu}^{-1}\right)$ was not significantly different from that of hams from slicing line B $\left(7.7 \pm 0.6 \log _{10} \mathrm{cfu}^{-1} \mathrm{~g}^{-1}\right)$. However, there were notable differences among ham samples, with a range of 4 to 9 log. Furthermore, we were intrigued that at a similar bacterial load, the mean decrease in $\mathrm{pH}$ from immediately after packaging $(6.15 \pm 0.06)$ to the UBD $(6.05 \pm 0.15)$ was significantly larger in samples from slicing line B (Fig. S5) and only when the bacterial load reached $7 \log _{10}$ cfu. $\mathrm{g}^{-1}$. This prompted us to analyze the possible correlation between decrease in $\mathrm{pH}$, production of volatile organic compounds, pyruvate-derived end-products, and population abundances of the different bacterial species present in the microbiota of the two slicing lines. 
From an initial screening of volatile organic compound production in hams, we noticed that the majority of VOCs were pyruvate-derived end-products, with ethanol representing around 90\% of the total volatilome (see supplementary data Fig. S6), followed by butan-2,3-dione and butan-2-one in smaller proportions. Compounds derived from amino-acid metabolism, such 2methylbutanal and 2-methyl-1-butanol, were also detected, but represented less than 5\% of the total volatilome. Because of this, we focused our subsequent analyses on the main pyruvate-derived end-products.

As shown in Fig. 7, an analysis of Pearson correlations revealed that decrease in $\mathrm{pH}$ was positively correlated to the production of D-lactic acid, acetic acid, and formic acid. The production of D-lactic acid was strongly correlated to that of ethanol and to the population abundance of Leuconostoc species (mainly L. carnosum). This observation is also illustrated in supplementary data Figure S7 showing the relationship between the production of endproducts and the population abundance of each of the bacterial species that were targeted as potential producers. Instead, the production of acetic acid also showed a strong positive correlation with that of formic acid and to many of the species that are co-occurring on ham from slicing line B; namely S. proteamaculans, C. maltaromaticum and V. fluvialis (and to a lesser extent with B. thermosphacta). C. maltaromaticum in particular showed the strongest correlation to the production of formic acid. As presented earlier in Fig. 4, L. carnosum, C. maltaromaticum, and S. proteamaculans were the most dominant species in samples from slicing line $B$, indicating that this type of microbiota may have a higher potential for spoilage than that of slicing line A. Conversely, the bacterial community of ham samples from slicing line $A$, in which these three species were subdominant with respect to $C$. divergens, correlated to lower production of these compounds. The production of L-lactic acid, on the other hand, was correlated to the abundance of $L$. sakei and $C$. mobile.

These results also prompted us to verify the effect of post-cooking factors (slicing line and $\mathrm{O}_{2}$ packaging permeability) on the metabolic indicators (see Fig. 8). With the exception of L-lactic acid, all compounds were present in higher concentrations in cooked ham from slicing line B. 
Furthermore, changes in the $\mathrm{O}_{2}$ permeability of the packaging resulted in a switch from L-lactic acid production (low $\mathrm{O}_{2}$ ) to acetic acid production (high $\mathrm{O}_{2}$ ).

\section{DISCUSSION}

The aim of this study was to perform a large-scale analysis of bacterial diversity in order to survey and characterize the influence of the processing steps in the microbial ecology of cooked ham. Among the various parameters described in previous studies and known to play a role in the variability of this food product, we have chosen five of them upstream or downstream of the cooking step. To do this, we focused on a single facility and deployed an extensive sampling strategy, with a complete factorial design and we applied it several times over four months of production to strengthen our findings. Our study shows evidences for the role of major and minor factors on both sides of the cooking steps that are driving the microbial ecology of cooked ham and hence the ham quality.

\subsection{After cooking, the slicing step creates most of the variability in ham bacterial communities and shapes the development of different spoilage metabolic profiles}

Our first unambiguous demonstration is that, the slicing line was the main source of variability in the microbial assemblages of ham. Although similar implication of the slicing equipment in bacterial contamination has been previously made by other scientists (Pothakos et al., 2012; Vasilopoulos et al., 2008), our analysis provides a better view of the impact that this process parameter is playing in ham quality. Indeed, in addition to prove that ham samples originating from the same batch of raw churned meat ended up with different bacterial communities based on the slicing line on which they had been cut after cooking, we demonstrate that each slicing line has a proper microbial fingerprint which remains rather stable in time. In the present case, the time spanned over several months from June to November during which the slicing lines were used several hundreds of times in the production unit between each sampling campaign. Furthermore, we show that the quality of cooked hams is also impacted by this specific 
processing step. It is important to remember here that the cooked ham samples that we analyzed at the UBD were generally not spoiled, and the production of spoilage metabolic indicators was usually very low. However, samples from line B showed higher production levels of fermentation-derived spoilage metabolites and a stronger $\mathrm{pH}$ decrease than those from line A. Unsurprisingly, production of D-lactic acid and ethanol was positively correlated with the prevalence and population abundance of species from the genus Leuconostoc (especially $L$. carnosum) and thus was more elevated in samples from line B. Such finding corroborates previous studies which showed that members of the Leuconostocaceae family are generally identified as strong putative spoilers, since their presence in high amounts in meat samples is often associated with gas production, greening, ethanol production and/or acidification (Björkroth et al., 1998; Comi and lacumin, 2012; Samelis et al., 1998; Raimondi et al., 2019). This finding is also consistent with two aspects of Leuconostoc biology. Firstly, the well-known heterolactic fermentation of glucose by species belonging to the Leuconostocaceae family under anaerobiosis (Cogan and Jordan, 1994; Dols et al., 1997) leading to lactate, acetate and ethanol as main end products. Secondly, the fact that Leuconostoc species preferentially produce D-lactate due to several D-lactate dehydrogenase-encoding genes in their genome.

Our results allowed us to draw similar conclusions on the impact of the slicing line on the production of acetic acid and formic acid (both with high correlation to $\mathrm{pH}$ decrease), increased in hams from line B when compared to hams from line A. The production of acetic acid by the ham microbiota is more challenging to interpret because, in addition to Leuconostocs species, several other species found on samples from line B can be involved in this process, most of which demonstrate co-occurrence relationships, such as C. maltaromaticum, $B$. thermosphacta, S. proteamaculans, and V. fluvialis. Nevertheless, our data are pointing out that the slicing line, as the main influencing factor on the microbiota structure, is modifying the production profile of these two acids. Thus, our results show that C. maltaromaticum and $S$. proteamaculans are the second confounding spoilers (after Leuconostocs) of cooked ham as they correlate with accumulation of acetic and formic acids. In particular, these two species 
distinguish themselves by specific production of formic acid in case of C. maltaromaticum, corroborating previous observations on Carnobacterium metabolism in meat (Borch and Molin, 1989; Zhang et al., 2019); and acetic acid by S. proteamaculans..

One of the reasons we suspect this Serratia species of being involved in acetic acid production is the influence played by the packaging with high $\mathrm{O}_{2}$ permeability on both parameters, thereby indicating that this processing factor is also playing a role in the microbial ecology of cooked ham. This post-cooking condition favored both higher concentrations of acetic acid and the growth of S. proteamaculans in samples sliced on line B, while it did not affect microbial communities of hams sliced on line A (mostly deprived of S. proteamaculans). It is known that this facultative anaerobic species grows preferentially in the presence of $\mathrm{O}_{2}$, as shown in a previous study of batch culture that compared growth with and without $\mathrm{O}_{2}$ (Alfaro et al., 2013). However, we were not able to detect oxygen in the packages of cooked ham at the UBD, indicating that when it permeates through the packaging, it is rapidly consumed by the microbiota and that S. proteamaculans alternates between quick aerobic respiration (when $\mathrm{O}_{2}$ permeates the packaging) and longer period of glucose fermentation to acetate (when the $\mathrm{O}_{2}$ is depleted).

\subsection{Raw meat microbiota is another source of bacterial variability between samples and has a sampling campaign effect}

Our data revealed that the composition of the cooked ham microbiota also depended on precooking parameters, in particular on the sampling campaign (different meat batches), but this effect was somewhat dependent of the slicing line and only specific groups of species are involved in this variability such as (e.g. L. mesenteroides and L. sakei in June or L. gelidum in September). Seasonal variability of raw meat microbiota has already been evidenced (Lucquin et al., 2012). However, our observation that a campaign-based effect can be evidenced on a cooked product raises the issue of the cooking step's effectiveness in eliminating initial meat microbiota. Indeed, such observation has already been done on cooked pork sausages (Hultman et al., 2015). Here, we clearly show that the cooking step eliminated about half of the 
bacterial species present, mainly those with low abundance on raw churned meat, such as Staphylococcus, Pseudomonas, and Yersinia; whereas some species were clearly introduced during production (re-contamination after cooking), such as V. fluvialis. Most interestingly, we show that the dominant bacterial species identified on cooked ham at UBD could be traced before and after cooking. We interpret this result as being the likely consequence of two phenomena :(1) there is a persistence of post-cooking living cells which could explain, for instance, why air raw meat transportation would influence the prevalence and abundance of S. proteamaculans or why churning speed would influence the relative abundance of $C$. divergens on cooked ham at UBD; (2) the slicing line is either a source of selection or a further source of contamination. Both assumptions cannot be refuted at this time, as the microbial ecology of the slicing lines was not included in this study. The two slicing lines studied in the factory are equipment from two different generations. Surprisingly, the newer line B of which the cutting mechanism is more complex than that of line A, produces ham with higher spoilage potential.

\section{CONCLUSIONS}

Our extensive survey of the microbiota of cooked ham from a single production unit provided us with a detailed view of the microbiota variability over a long production time and to characterize the ways in which the microbial ecology of this product is shaped by the various processing steps. Our results clearly demonstrate that the process (and especially the slicing step) has a more important microbial fingerprint than the raw meat on the final communities of cooked ham. This study illustrates the very important role this type of strategy could play in the food industry if applied more broadly to process management, such as for instance, defining more precise UBD according to the conditions of production. 


\section{TABLES}

TABLE 1 Levels of the different processing steps

\begin{tabular}{|c|c|c|c|}
\hline Processing step & Description of the step variations & $\begin{array}{l}\text { Labeling } \\
\text { of levels }\end{array}$ & Description of the levels analyzed in this study \\
\hline Meat transportation & $\begin{array}{l}\text { Time and storage conditions of the transportation of pork meat } \\
\text { from slaughterhouse to the ham factory may vary as a function } \\
\text { of meat origin. }\end{array}$ & $\begin{array}{l}\text { Vacuum } \\
\text { Air }\end{array}$ & $\begin{array}{l}\text { Storage in vacuum packaging for ten days at } 4^{\circ} \mathrm{C} \\
\text { Storage in open air for three days at } 4^{\circ} \mathrm{C}\end{array}$ \\
\hline Churning & $\begin{array}{l}\text { During ham production, the number of churning rotations is a } \\
\text { constant but pause time between two rotation sessions may } \\
\text { vary in response to the arrival of meat batches and staff } \\
\text { organization. }\end{array}$ & Slow & $\begin{array}{l}\text { Standard quick churning at } 4^{\circ} \mathrm{C} \text {, carried out during the workweek } \\
\text { Slow churning (four times longer than standard churning) at } 4^{\circ} \mathrm{C} \text {, } \\
\text { carried out during the weekend }\end{array}$ \\
\hline Drain-off & $\begin{array}{l}\text { The drain-off time after cooking may be modified in response } \\
\text { to production demand. }\end{array}$ & $\begin{array}{l}\text { Long } \\
\text { Short }\end{array}$ & $\begin{array}{l}\text { Drain-off for twelve days at } 4^{\circ} \mathrm{C} \text { when production demand is low. } \\
\text { Drain-off for four days at } 4^{\circ} \mathrm{C} \text { when production demand is high. }\end{array}$ \\
\hline $\begin{array}{l}\mathrm{O}_{2} \text { packaging } \\
\text { permeability }\end{array}$ & $\begin{array}{l}\text { The film used for sealing the modified atmosphere packaging } \\
\text { may vary in its degree of permeability to } \mathrm{O}_{2} \text {. }\end{array}$ & Low O2 & $\begin{array}{l}\text { Single-layer APET packaging (amorphous polyethylene } \\
\text { terephthalate) has an } \mathrm{O}_{2} \text { permeability of } 16.3 \mathrm{~cm}^{3} \cdot \mathrm{m}^{-2} \cdot \text { day. } 10^{5} \mathrm{~Pa} \text {. } \\
\text { Multiple-layer polyvinyl chloride/vinylic ethylene alcohol/polyethylene } \\
\text { packaging has an } \mathrm{O}_{2} \text { permeability of } 1.24 \mathrm{~cm}^{3} \cdot \mathrm{m}^{-2} \cdot \text { day. } 10^{5} \mathrm{~Pa} \text {. }\end{array}$ \\
\hline
\end{tabular}


TABLE 2 Comparative table showing the number of species (after merging OTUs with similar taxonomic assignments) identified in different subsets of samples

\begin{tabular}{|c|c|c|c|}
\hline & \multicolumn{3}{|c|}{ Sample subsets } \\
\cline { 2 - 4 } & $\begin{array}{c}\text { Churned meat } \\
\text { (15 samples) }\end{array}$ & $\begin{array}{c}\text { Ham at UBD } \\
\text { (92 samples) }\end{array}$ & $\begin{array}{c}\text { Hams past UBD } \\
\text { (108 samples) }\end{array}$ \\
\hline Campaign 1 * & - & $16 \pm 3$ & $13 \pm 4$ \\
\hline Campaign 2 * & $50 \pm 8$ & $13 \pm 4$ & $14 \pm 5$ \\
\hline Campaign 3* & $41 \pm 10$ & $13 \pm 6$ & $14 \pm 7$ \\
\hline Campaign 4 * & - & $14 \pm 7$ & $25 \pm 6$ \\
\hline Total number of species & 55 & 43 & 44 \\
\hline
\end{tabular}

* Mean number of species 


\section{LEGENDS TO THE FIGURES.}

\section{FIG 1 Ham sampling strategy.}

Sampling strategy based on a complete factorial design, with two levels for each of the five processing steps: meat transportation, churning, drain-off, slicing, and $\mathrm{O}_{2}$ packaging permeability.

FIG 2 Ward unsupervised clustering of the microbiota of cooked ham samples according to Bray-Curtis dissimilarity index.

The clustering analysis revealed two main clusters which were further subdivided into several clusters of various sample sizes. Below the clustering tree is a species composition plot (relative abundance) for the fourteen most-abundant species.

FIG 3 Non-metric multi-dimensional scaling analysis of cooked ham microbiotas based on Bray-Curtis dissimilarity index.

Panel P1: The bacterial assemblage of each cooked ham sample is represented by a dot, colored according to the slicing line on which the ham was processed (red = slicing line B; pink = slicing line A). Panels P2 and P3: cooked ham assemblages were subdivided based on slicing line (most discriminant parameter), and each subset (line A in panel P2; line B in panel P3) was analyzed separately, with the samples colored according to their sampling campaign of origin (blue = campaign $\mathrm{C} 1$; red = campaign $\mathrm{C} 2$; green = campaign $\mathrm{C} 3$; pink = campaign C4). The other processing steps had no influence in structuring overall bacterial diversity (see supplementary Fig. S4). For slicing line and sampling campaign, differences in composition between the bacterial communities present in the tested conditions were estimated using permutational ANOVA. Corresponding $\mathrm{p}$-values are indicated under each plot.

FIG 4 Species composition plots of cooked ham microbiota separated by slicing line and sampling campaign. 
Bar plots show the relative abundance of the fourteen core bacterial species in cooked ham. Cooked ham samples are distributed vertically by slicing line of origin (top = samples from line $\mathrm{A}$; bottom = samples from line $\mathrm{B})$. Within each slicing line, ham samples are distributed horizontally according to the four main bacterial genera present (from left to right: Carnobacterium, Lactobacillus, Leuconostoc, and Serratia) and then according to sampling campaign ( $\mathrm{C} 1$ to $\mathrm{C} 4)$.

FIG 5 Comparative analysis of the relative abundance of S. proteamaculans and $C$. divergens in cooked ham samples as a function of processing parameters.

Panel P1: relative abundance (in number of reads) of S. proteamaculans in samples from slicing line B as a function of the other processing parameters. Panel P2: relative abundance (in number of reads) of $C$. divergens in samples from slicing line $A$ as a function of the other processing parameters. Statistical variance between groups of samples was determined with ANOVA followed by a Student's t-test. The number of stars indicate the $p$-value: ${ }^{\star \star \star} p$-value $<$ $0.001 ;{ }^{* *}$ p-value $<0.01 ;{ }^{*}$-value $<0.05$

\section{FIG 6 Heatmap depicting the effect of cooking on bacterial species abundances in ham.}

Samples from campaigns C2 and C3 are ordered according to the sample type: left, raw meat after churning, and right, cooked ham at UBD. Bacterial species are ordered in three groups from top to bottom: species present only before cooking (hence eliminated by the cooking step), species present before and after cooking (either resistant to cooking or reintroduced after cooking), and species present only after cooking (contamination). Within each group, species are ordered by their taxonomic relationships. Species names colored in red, blue, or green indicate placement within the phyla Firmicutes, Proteobacteria, or Actinobacteria, respectively. Stars indicate the fourteen most-abundant species in cooked ham. The scale in the top-right corner of the heatmap depicts the color palette associated with the relative numbers of reads of the various species. The black vertical line represents the cooking step. 
FIG 7 Correlation plot representing the Pearson coefficient between the production of end-products from the mixed-acid fermentation of pyruvate and the estimated load of bacterial species on cooked ham at the UBD.

Fermentation end-products are vertically distributed according to the difference between the final concentration at the UBD and the initial concentration just after packaging. The absolute load of each bacterial species is distributed horizontally and was estimated using the total bacterial load weighted by each species' relative abundance (percentage; see Materials \& Methods). The Pearson correlation coefficient between the production of an end-product and the estimated load of a bacterial species is represented by a colored square. The scale on the right depicts the color palette associated with the value of the Pearson correlation coefficient (red, white, and blue corresponding respectively to a negative correlation, no correlation, and a positive correlation).

FIG 8 Box plots of the production in $\mathrm{mg}^{-1}$ of end-products from the mixed-acid fermentation of pyruvate as a function of the estimated load of bacterial species at the UBD.

For each graph, all UBD samples were sorted according to their estimated load of a species of interest within the bacterial community (e.g., samples were sorted according to their estimated load of C. maltaromaticum). Samples for which the estimated load of the species of interest was less than $2 \log _{10} \mathrm{cfu}_{\mathrm{g}} \mathrm{g}^{-1}$ were not included in order to focus on samples in which the species was relevant. In some cases, high bacterial loads were not attributable to an identified species and were labeled "NA". B. thermosphacta and C. mobile were not included because they were present in too few samples to allow box plot representation. Panels depict the relationships for different metabolites, from P1 (D-lactic acid) to P5 (formic acid), presented by decreasing average production levels.

FIG S1 Management of sampling to optimize operational process requirements. 
The ham production schedule for a single campaign is shown as a function of variations in the length of the different steps (depicted in days at the top of the figure). After slicing and packing, ham samples (represented by red and yellow ellipses) were collected for all campaigns (C1 to C4), whereas meat samples were collected before cooking (represented by green ellipses) for campaigns C2 and C3 only.

FIG S2 Principal Coordinates analysis based on Bray-Curtis dissimilarity index to compare ham microbial communities of samples using gyrB and 16S rDNA amplicon sequencing.

Samples S1 to S14 are labeled "gyrB" or "16S" according to the molecular marker used for bacterial identification. Samples from the four different sampling campaigns (C1 to C4) are represented: S1 from campaign C1; S2 to S4 from campaign C2; S5 to S10 from campaign C3; S11 to S14 from campaign C4. Samples S1, S4, S5, S8, S10 and S13 were sliced on line A and samples S2, S3, S6, S7, S9, S11, S12 and S14 on line B.

FIG S4 Non-metric multi-dimensional analysis of cooked ham samples based on BrayCurtis dissimilarity index.

Samples were analyzed in two separated subsets, corresponding to samples from line A on the left side and samples from line B on the right side. Within a given subset of samples, ham samples were colored either according to: the sampling campaign (blue=C1; red=C2; green=C3; pink=C4); the churning speed (dark blue=slow; light blue=quick); the $\mathrm{O}_{2}$ packaging permeability (dark green=high $\mathrm{O}_{2}$; light green=low $\mathrm{O}_{2}$ ); the conditions of transportation of raw meat (yellow=air; orange=vacuum); the drain-off time after cooking (dark grey=long; light grey=short); the shelf-life (light purple=UBD; dark purple=past UBD). For each graph, differences in composition between bacterial communities present in the two tested conditions were estimated using permutational ANOVA. Corresponding $p$-values are indicated under each plot. 
FIG S5 Boxplots depicting the decrease in $\mathrm{pH}$ of ham samples from slicing lines $\mathrm{A}$ and B as a function of total bacterial load.

Bacterial load is represented in $\log _{10} \mathrm{cfu}^{-1} \mathrm{~g}^{-1}$. Samples were segregated by their slicing line of origin and then sorted by their bacterial load, ranging from 4 to $9 \log _{10} \mathrm{Cfu} . \mathrm{g}^{-1}$. Delta pH depicts the difference between the initial $\mathrm{pH}$ measured just after packaging and the $\mathrm{pH}$ at the UBD. Statistical variance between groups of samples within a slicing line was determined with a Mann \& Whitney test. The number of stars indicates the $p$-value: * $p$-value $<0.05$; "ns" for $p$ value $>0.05$

FIG S6 Boxplots showing the percentage of total emitted volatile compounds of hams at UBD.

Samples from campaigns C1 and C2 are represented. The compounds are ordered from left to right in decreasing order of abundance.

FIG S7 Boxplots showing the production level in $\mathrm{mg}^{-\mathrm{g}^{-1}}$ of end products from mixedacid fermentation of pyruvate according to the estimated load of bacterial species at UBD.

For each graph, all UBD samples were sorted according to their estimated load of a species of interest within bacterial communities (e.g. samples are sorted according to their estimated load of C. maltaromaticum). Samples where the estimated load of the species of interest was under $2 \log _{10}$ cfu.g $\mathrm{g}^{-1}$ were not represented, in order to focus on samples where the species was representative. For some species, high loads were non-attributed and were labeled "NA". B. thermosphacta and C. mobile were not represented since they were present in too few samples to allow boxplot representation. Metabolites are ordered in Panels, from P1 (D-lactic acid) to P5 (formic acid) by average decreasing production levels. 


\section{ACKNOWLEDGMENTS}

We thank the MIGALE bioinformatics platform at INRA (http://migale.jouy.inra.fr) for providing computational resources and data storage. We also thank the INRA @BRIDGe platform for carrying out the MiSeq sequencing runs. Marine ZAGDOUN was the recipient of ANRT grant number 2016/1038 (Association Nationale de la Recherche et de la Technologie, lle de France). The funders had no role in the study's design, data collection, and interpretation, or the decision to submit the work for publication. 


\section{REFERENCES}

Alfaro, B., Hernández, I., Le Marc, Y., Pin, C., 2013. Modelling the effect of the temperature and carbon dioxide on the growth of spoilage bacteria in packed fish products. Food Control, Predictive Modelling of Food Quality and Safety 29, 429-437. https://doi.org/10.1016/j.foodcont.2012.05.046

Audenaert, K., D'Haene, K., Messens, K., Ruyssen, T., Vandamme, P., Huys, G., 2010. Diversity of lactic acid bacteria from modified atmosphere packaged sliced cooked meat products at sell-by date assessed by PCR-denaturing gradient gel electrophoresis. Food Microbiol. 27, 12-18. https://doi.org/10.1016/j.fm.2009.04.006

Barret, M., Briand, M., Bonneau, S., Préveaux, A., Valière, S., Bouchez, O., Hunault, G., Simoneau, P., Jacques, M.-A., 2015. Emergence Shapes the Structure of the Seed Microbiota. Appl. Environ. Microbiol. 81, 1257-1266. https://doi.org/10.1128/AEM.03722-14

Benson, A.K., David, J.R.D., Gilbreth, S.E., Smith, G., Nietfeldt, J., Legge, R., Kim, J., Sinha, R., Duncan, C.E., Ma, J., Singh, I., 2014. Microbial Successions Are Associated with Changes in Chemical Profiles of a Model Refrigerated Fresh Pork Sausage during an 80-Day Shelf Life Study. Appl. Environ. Microbiol. 80, 5178-5194. https://doi.org/10.1128/AEM.00774-14

Björkroth, K.J., Korkeala, H.J., 1997. Use of rRNA gene restriction patterns to evaluate lactic acid bacterium contamination of vacuum-packaged sliced cooked whole-meat product in a meat processing plant. Appl. Environ. Microbiol. 63, 448-453.

Björkroth, K.J., Vandamme, P., Korkeala, H.J., 1998. Identification and Characterization of Leuconostoc carnosum, Associated with Production and Spoilage of Vacuum-Packaged, Sliced, Cooked Ham. Appl. Environ. Microbiol. 64, 3313-3319.

Bokulich, N.A., Subramanian, S., Faith, J.J., Gevers, D., Gordon, J.I., Knight, R., Mills, D.A., Caporaso, J.G., 2013. Quality-filtering vastly improves diversity estimates from Illumina amplicon sequencing. Nat. Methods 10, 57-59. https://doi.org/10.1038/nmeth.2276

Borch, E., Molin, G., 1989. The aerobic growth and product formation of Lactobacillus, Leuconostoc, Brochothrix, and Carnobacterium in batch cultures. Appl. Microbiol. Biotechnol. 30, 81-88. https://doi.org/10.1007/BF00256001

Camacho, C., Coulouris, G., Avagyan, V., Ma, N., Papadopoulos, J., Bealer, K., Madden, T.L., 2009. BLAST+: architecture and applications. BMC Bioinformatics 10, 421. https://doi.org/10.1186/1471-2105-10-421

Chaillou, S., Chaulot-Talmon, A., Caekebeke, H., Cardinal, M., Christieans, S., Denis, C., Hélène Desmonts, M., Dousset, X., Feurer, C., Hamon, E., Joffraud, J.-J., La Carbona, S., Leroi, F., Leroy, S., Lorre, S., Macé, S., Pilet, M.-F., Prévost, H., Rivollier, M., Roux, D., Talon, R., Zagorec, M., Champomier-Vergès, M.-C., 2015. Origin and ecological selection of core and food-specific bacterial communities associated with meat and seafood spoilage. ISME J. 9, 1105-1118. https://doi.org/10.1038/ismej.2014.202

Chessel, D., Dufour, A.B., Thioulouse, J., 1987. The ade 4 package-I : One-table methods.

Cogan, T.M., Jordan, K.N., 1994. Metabolism of Leuconostoc Bacteria. J. Dairy Sci. 77, 2704-2717. https://doi.org/10.3168/jds.S0022-0302(94)77213-1

Comi, G., lacumin, L., 2012. Identification and process origin of bacteria responsible for cavities and volatile off-flavour compounds in artisan cooked ham. Int. J. Food Sci. Technol. 47, 114-121.

Dols, M., Chraibi, W., Remaud-Simeon, M., Lindley, N.D., Monsan, P.F., 1997. Growth and energetics of Leuconostoc mesenteroides NRRL B-1299 during metabolism of various sugars and their consequences for dextransucrase production. Appl. Environ. Microbiol. 63, 2159-2165.

Dušková, M., Kameník, J., Lačanin, I., Šedo, O., Zdráhal, Z., 2016. Lactic acid bacteria in cooked hams Sources of contamination and chances of survival in the product. Food Control 61, 1-5. https://doi.org/10.1016/j.foodcont.2015.09.019 
Escudié, F., Auer, L., Bernard, M., Mariadassou, M., Cauquil, L., Vidal, K., Maman, S., HernandezRaquet, G., Combes, S., Pascal, G., 2018. FROGS: Find, Rapidly, OTUs with Galaxy Solution. Bioinforma. Oxf. Engl. 34, 1287-1294. https://doi.org/10.1093/bioinformatics/btx791

Fougy, L., Desmonts, M.-H., Coeuret, G., Fassel, C., Hamon, E., Hézard, B., Champomier-Vergès, M.-C., Chaillou, S., 2016. Reducing Salt in Raw Pork Sausages Increases Spoilage and Correlates with Reduced Bacterial Diversity. Appl. Environ. Microbiol. 82, 3928-3939. https://doi.org/10.1128/AEM.00323-16

Gascuel, O., 1997. BIONJ: an improved version of the NJ algorithm based on a simple model of sequence data. Mol. Biol. Evol. 14, 685-695. https://doi.org/10.1093/oxfordjournals.molbev.a025808

Geeraerts, W., Pothakos, V., De Vuyst, L., Leroy, F., 2017. Diversity of the dominant bacterial species on sliced cooked pork products at expiration date in the Belgian retail. Food Microbiol. 65, 236-243. https://doi.org/10.1016/j.fm.2017.03.007

Gouy, M., Guindon, S., Gascuel, O., 2010. SeaView version 4: A multiplatform graphical user interface for sequence alignment and phylogenetic tree building. Mol. Biol. Evol. 27, 221-224. https://doi.org/10.1093/molbev/msp259

Han, Y., Jiang, Y., Sun, X., Xu, B., Zhou, G., 2011. Effect of high pressure treatment on microbial populations of sliced vacuum-packed cooked ham. Meat Sci. 682-688.

Hultman, J., Rahkila, R., Ali, J., Rousu, J., Björkroth, K.J., 2015. Meat Processing Plant Microbiome and Contamination Patterns of Cold-Tolerant Bacteria Causing Food Safety and Spoilage Risks in the Manufacture of Vacuum-Packaged Cooked Sausages. Appl. Environ. Microbiol. 81, 70887097. https://doi.org/10.1128/AEM.02228-15

Kim, O.-S., Cho, Y.-J., Lee, K., Yoon, S.-H., Kim, M., Na, H., Park, S.-C., Jeon, Y.S., Lee, J.-H., Yi, H., Won, S., Chun, J., 2012. Introducing EzTaxon-e: a prokaryotic 16S rRNA gene sequence database with phylotypes that represent uncultured species. Int. J. Syst. Evol. Microbiol. 62, 716-721. https://doi.org/10.1099/ijs.0.038075-0

Kimura, M., 1980. A simple method for estimating evolutionary rates of base substitutions through comparative studies of nucleotide sequences. J. Mol. Evol. 16, 111-120.

Klindworth, A., Pruesse, E., Schweer, T., Peplies, J., Quast, C., Horn, M., Glöckner, F.O., 2013. Evaluation of general $16 \mathrm{~S}$ ribosomal RNA gene PCR primers for classical and next-generation sequencing-based diversity studies. Nucleic Acids Res. 41, e1. https://doi.org/10.1093/nar/gks808

Lucquin, I., Zagorec, M., Champomier-Vergès, M., Chaillou, S., 2012. Fingerprint of lactic acid bacteria population in beef carpaccio is influenced by storage process and seasonal changes. Food Microbiol., Fermented MeatsFermented Meats 29, 187-196. https://doi.org/10.1016/j.fm.2011.08.001

Mahé, F., Rognes, T., Quince, C., Vargas, C. de, Dunthorn, M., 2014. Swarm: robust and fast clustering method for amplicon-based studies. PeerJ 2, e593. https://doi.org/10.7717/peerj.593

Martin, M., 2011. Cutadapt removes adapter sequences from high-throughput sequencing reads. EMBnet.journal 17, 10-12. https://doi.org/10.14806/ej.17.1.200

McMurdie, P.J., Holmes, S., 2013. phyloseq: an R package for reproducible interactive analysis and graphics of microbiome census data. PloS One 8, e61217. https://doi.org/10.1371/journal.pone.0061217

Mol, J.H.H., Hietbrink, J.E.A., Mollen, H.W.M., Tinteren, J.V., 1971. Observations on the Microflora of Vacuum Packed Sliced Cooked Meat Products. J. Appl. Bacteriol. 34, 377-397. https://doi.org/10.1111/j.1365-2672.1971.tb02297.x

Piotrowska-Cyplik, A., Myszka, K., Czarny, J., Ratajczak, K., Kowalski, R., Biegańska-Marecik, R., Staninska-Pięta, J., Nowak, J., Cyplik, P., 2017. Characterization of specific spoilage organisms (SSOs) in vacuum-packed ham by culture-plating techniques and MiSeq next-generation sequencing technologies. J. Sci. Food Agric. 97, 659-668. https://doi.org/10.1002/jsfa.7785

Poirier, S., Rué, O., Coeuret, G., Champomier-Vergès, M.-C., Loux, V., Chaillou, S., 2018a. Detection of an amplification bias associated to Leuconostocaceae family with a universal primer routinely 
used for monitoring microbial community structures within food products. BMC Res. Notes 11. https://doi.org/10.1186/s13104-018-3908-2

Poirier, S., Rué, O., Peguilhan, R., Coeuret, G., Zagorec, M., Champomier-Vergès, M.-C., Loux, V., Chaillou, S., 2018b. Deciphering intra-species bacterial diversity of meat and seafood spoilage microbiota using gyrB amplicon sequencing: A comparative analysis with 16S rDNA V3-V4 amplicon sequencing. PloS One 13, e0204629. https://doi.org/10.1371/journal.pone.0204629

Pothakos, V., Samapundo, S., Devlieghere, F., 2012. Total mesophilic counts underestimate in many cases the contamination levels of psychrotrophic lactic acid bacteria (LAB) in chilled-stored food products at the end of their shelf-life. Food Microbiol. 32, 437-443. https://doi.org/10.1016/j.fm.2012.07.011

Quast, C., Pruesse, E., Yilmaz, P., Gerken, J., Schweer, T., Yarza, P., Peplies, J., Glöckner, F.O., 2013. The SILVA ribosomal RNA gene database project: improved data processing and web-based tools. Nucleic Acids Res. 41, D590-D596. https://doi.org/10.1093/nar/gks1219

Raimondi, S., Luciani, R., Sirangelo, T.M., Amaretti, A., Leonardi, A., Ulrici, A., Foca, G., D'Auria, G., Moya, A., Zuliani, V., Seibert, T.M., Søltoft-Jensen, J., Rossi, M., 2019. Microbiota of sliced cooked ham packaged in modified atmosphere throughout the shelf life: Microbiota of sliced cooked ham in MAP. Int. J. Food Microbiol. 289, 200-208. https://doi.org/10.1016/j.ijfoodmicro.2018.09.017

Samelis, J., Kakouri, A., Georgiadou, K.G., Metaxopoulos, J., 1998. Evaluation of the extent and type of bacterial contamination at different stages of processing of cooked ham. J. Appl. Microbiol. 84, 649-660.

Stellato, G., La Storia, A., De Filippis, F., Borriello, G., Villani, F., Ercolini, D., 2016. Overlap of SpoilageAssociated Microbiota between Meat and the Meat Processing Environment in Small-Scale and Large-Scale Retail Distributions. Appl. Environ. Microbiol. 82, 4045-4054. https://doi.org/10.1128/AEM.00793-16

Vasilopoulos, C., De Maere, H., De Mey, E., Paelinck, H., De Vuyst, L., Leroy, F., 2010. Technologyinduced selection towards the spoilage microbiota of artisan-type cooked ham packed under modified atmosphere. Food Microbiol. 27, 77-84. https://doi.org/10.1016/j.fm.2009.08.008

Vasilopoulos, C., Ravyts, F., De Maere, H., De Mey, E., Paelinck, H., De Vuyst, L., Leroy, F., 2008. Evaluation of the spoilage lactic acid bacteria in modified-atmosphere-packaged artisan-type cooked ham using culture-dependent and culture-independent approaches. J. Appl. Microbiol. 104, 1341-1353. https://doi.org/10.1111/j.1365-2672.2007.03664.x

Wang, Q., Garrity, G.M., Tiedje, J.M., Cole, J.R., 2007. Naive Bayesian classifier for rapid assignment of rRNA sequences into the new bacterial taxonomy. Appl. Environ. Microbiol. 73, 52615267. https://doi.org/10.1128/AEM.00062-07

Wheatley, P., Giotis, E.S., McKevitt, A.I., 2014. Effects of slaughtering operations on carcass contamination in an Irish pork production plant. Ir. Vet. J. 67, 1. https://doi.org/10.1186/2046-0481-67-1

Wickham, H., 2010. ggplot2: Elegant Graphics for Data Analysis, 1st ed. 2009. Corr. 3rd printing 2010. ed. Springer-Verlag New York Inc., New York.

Zhang, J., Kobert, K., Flouri, T., Stamatakis, A., 2014. PEAR: a fast and accurate Illumina Paired-End reAd mergeR. Bioinforma. Oxf. Engl. 30, 614-620. https://doi.org/10.1093/bioinformatics/btt593 


\section{Raw meat}

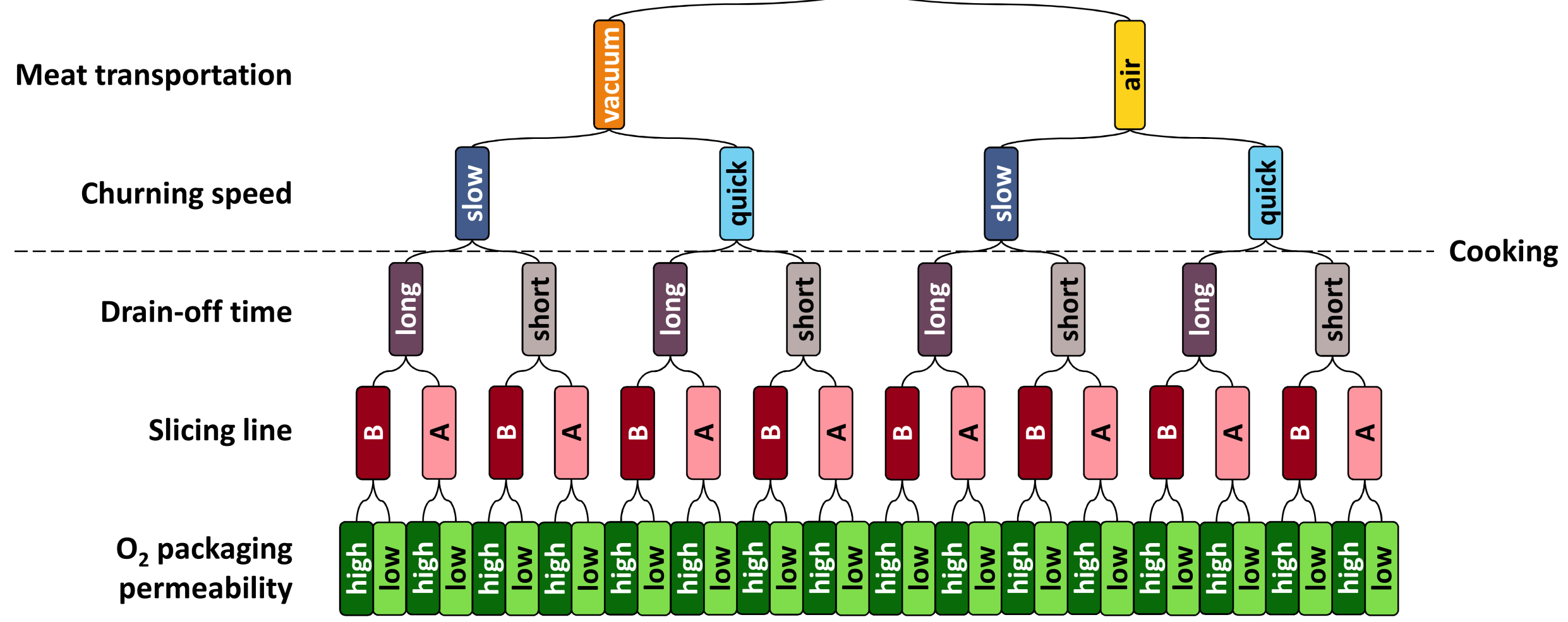

32 ham samples per campaign 

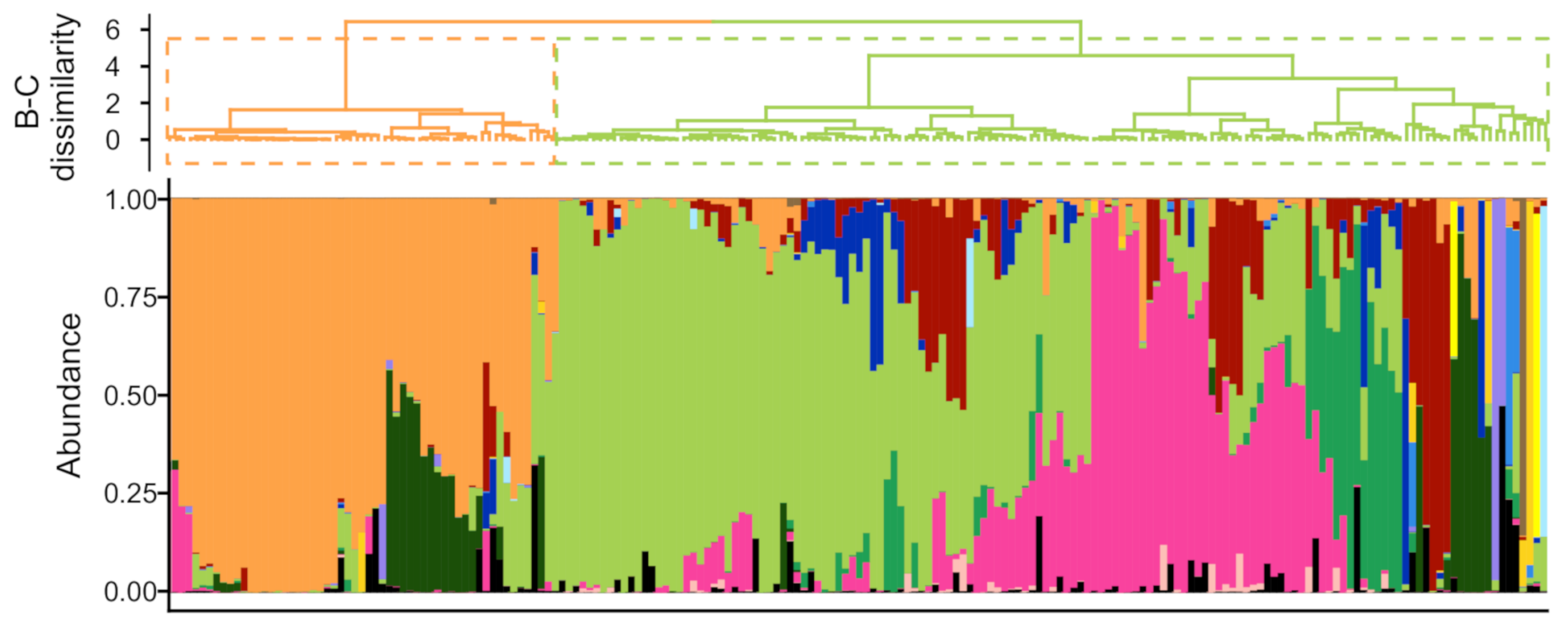

Carnobacterium divergens

Carnobacterium maltaromaticum Carnobacterium mobile Carnobacterium sp.
Lactobacillus sakei Lactobacillus algidus Lactobacillus paraplantarum Lactobacillus oligofermentans
Leuconostoc carnosum Leuconostoc gelidum Leuconostoc mesenteroides
Brochothrix thermosphacta Vagococcus fluvialis Serratia proteamaculans Other 
P1

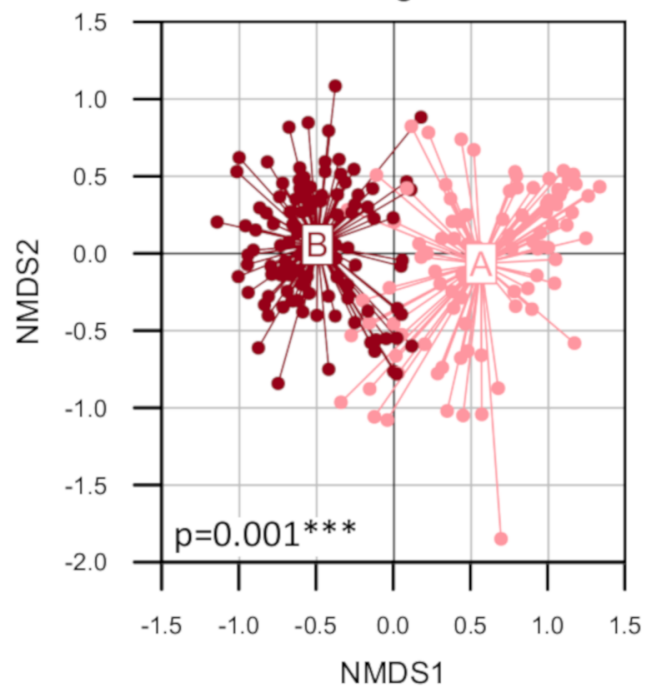

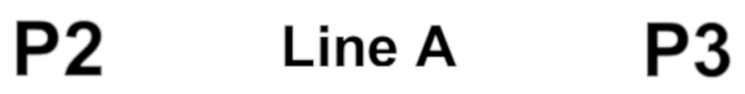

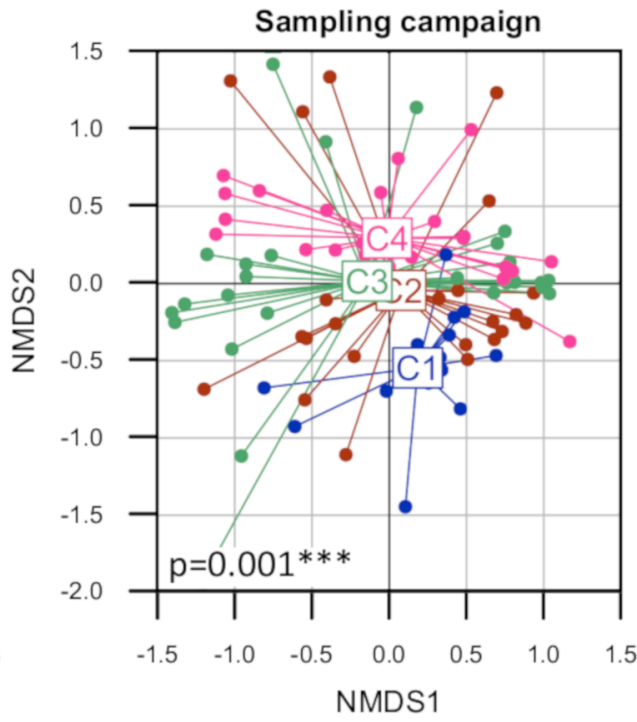

Line B

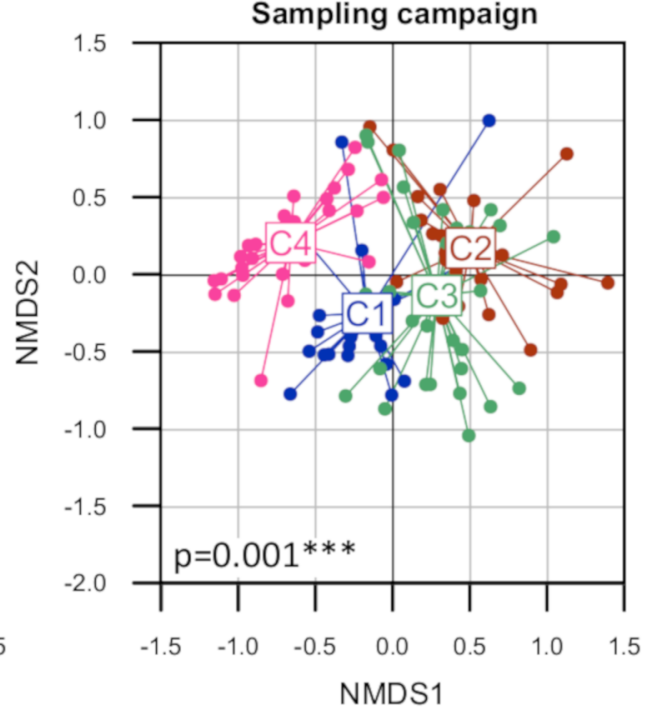


Sampling campaign

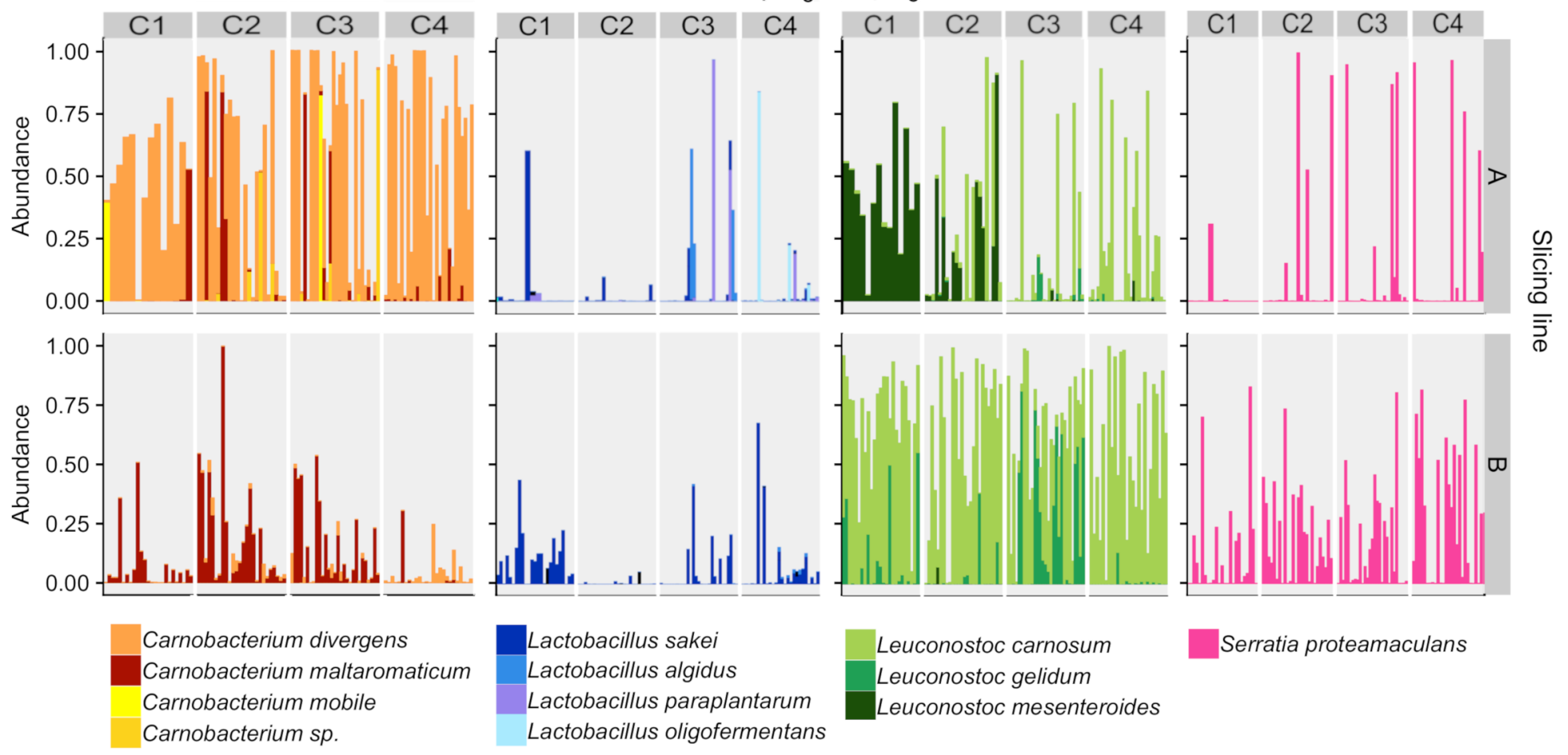




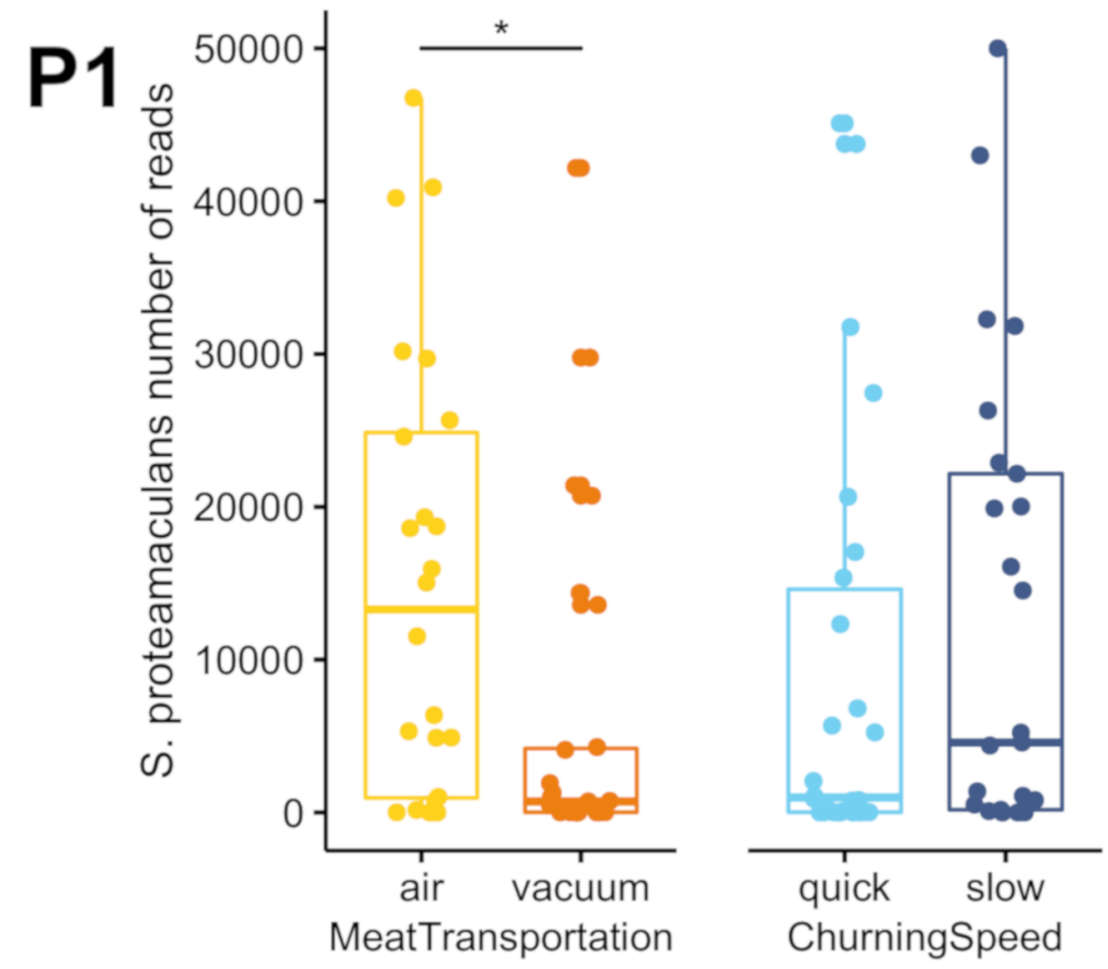

P2
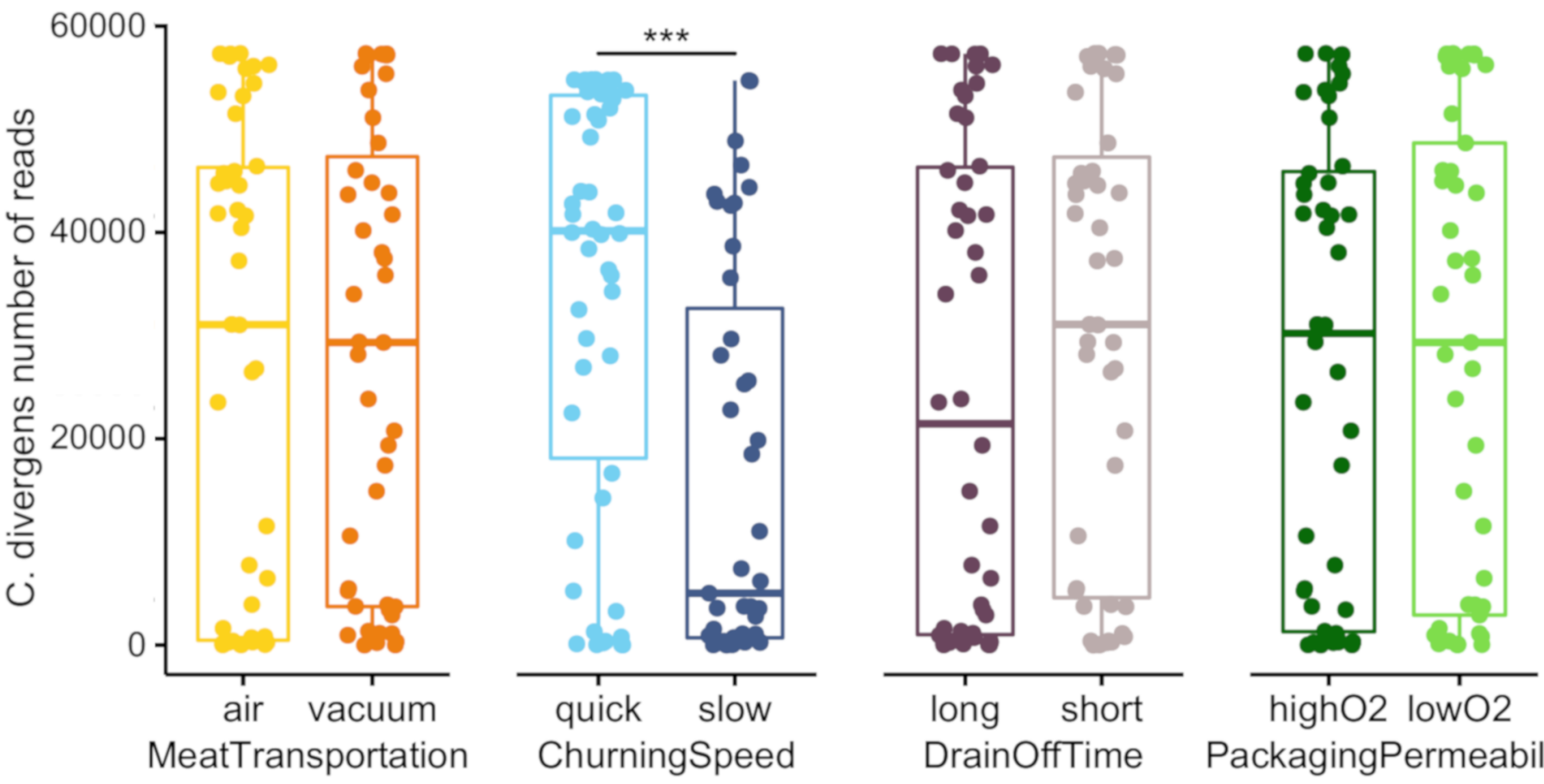

PackagingPermeability 
Staphylococcus sp. Staphylococcus carnosus-subsp-utilis

Enterococcus sp.

Lactococcus garvieae Lactococcus lactis-subsp-lactis

Lactococcus $s p$.

Lactobacillus plantarum

Weissella viridescens

Weissella hellenica

Cutibacterium acnes Lelliottia $s p$.

Psychrobacter sp.

Acinetobacter $s p$.

Acinetobacter /wofii

Shewanella baltica Vibrio sp. Kocuria sp.

Burkholderia sp.

Janthinobacterium svalbardensis

Comamonas testosteroni

Comamonas aquatica

Delftia acidovorans

Neisseria meningitidis

Pseudomonas psychrotolerans

Pseudomonas chlororaphis

Pseudomonas sp.

* Brochothrix thermosphacta

* Carnobacterium maltaromaticum

D
$\frac{\mathbb{U}}{0}$
$\frac{0}{0}$

* Carnobacterium divergens Lactococcus piscium

Vagococcus fessus

* Lactobacillus algidus

Lactobacillus fuchuensis

* Lactobacillus sakei

Lactobacillus curvatus

Leuconostoc gelidum-subsp-gasicomitatum

* Leuconostoc gelidum-subsp-gelidum

* Leuconostoc mesenteroides

* Leuconostoc carnosum Leuconostoc sp.

Yersinia $s p$.

Rouxiella $s p$.

Serratia liquefasciens Serratia $s p$.

* Serratia proteamaculans Acinetobacter harbinensis Psychrobacter cibarius Photobacterium iliopiscarium Aeromonas hydrophila Aeromonas salmonicida-subsp-pectinolytica

Pseudomonas lundensis

Pseudomonas fluorescens

Pseudomonas psychrophila Pseudomonas fragi Enterococcus malodoratus

* Carnobacterium sp.

* Carnobacterium mobile Vagococcus sp.

* Vagococcus fluvialis

* Lactobacillus oligofermentans

* Lactobacillus paraplantarum Lactobacillus brevis Lactobacillus paracasei Proteus mirabilis Providencia $s p$.

Providencia heimbachae Morganella psychrotolerans Hafnia paralvei

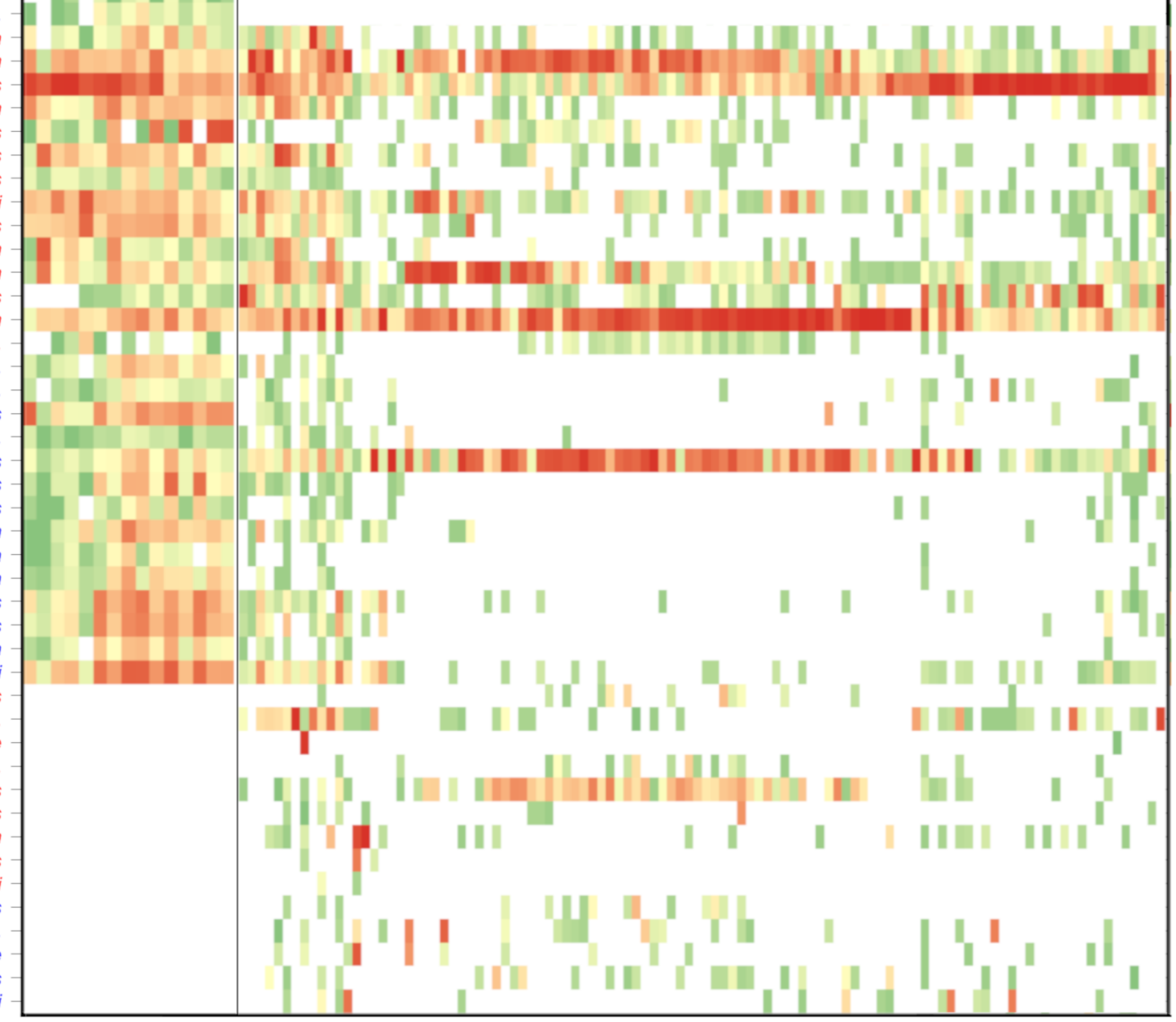

Samples

Abundance

10000

100

$-1$ 


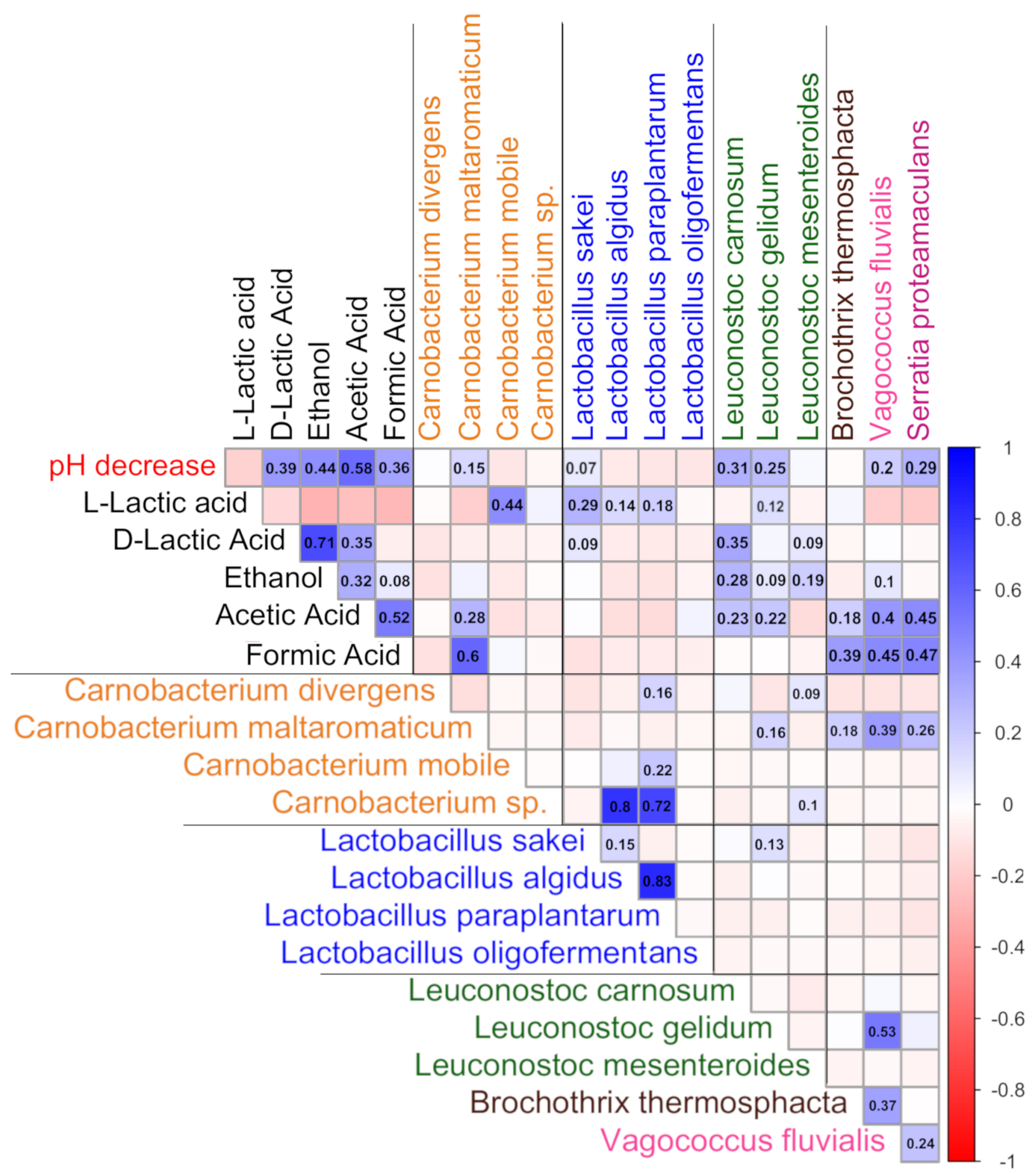


